\begin{tabular}{l} 
JURNAI R AS'II \\
IAll $\begin{array}{l}\text { (Rekayasa Sistem dan Teknologi Informasi) } \\
\text { Vol. 6 No. 1 (2022) } 16-24\end{array}$ \\
\hline
\end{tabular}

\title{
Optimization of the Fuzzy Logic Method for Autism Spectrum Disorder Diagnosis
}

\author{
Linda Perdana Wanti ${ }^{1}$, Lina Puspitasari ${ }^{2}$ \\ ${ }^{1}$ Department of Informatics, Politeknik Negeri Cilacap \\ ${ }^{2}$ Department of Midwifery, Akbid Graha Mandiri Cilacap \\ ${ }^{1}$ linda_perdana@pnc.ac.id, ${ }^{2}$ lina_puspitasari@yahoo.com
}

\begin{abstract}
Diagnosis of autism spectrum disorder (ASD) can use a fuzzy inference system. The use of fuzzy logic method to obtain ASD diagnosis results according to experts based on the limits of factors/symptoms of the disease and all the rules obtained from experts. Recommendations for therapy and preventive actions can be given by experts after knowing the results of the diagnosis of ASD using the fuzzy logic method. This study serves to diagnose ASD by optimizing each degree of membership in the fuzzy logic method with the Mamdani method approach which is involved in the autism detection process involving 96 patient data. The Mamdani method itself can process an uncertain value from the user/patient into a definite value whose membership degree can be determined and adjusted to the conditions of the problem. Optimization was carried out on the degree of membership for all variables involved in the process of diagnosing ASD, namely social interaction, social communication and imagination and behavior patterns. The results of this study indicate a relatively small level of fuzzy calculation error with a precision value of $94.4 \%$, a recall precision value of $65.4 \%$ and an error rate value of $3.05 \%$. Calculation of accuracy shows a result of $90.59 \%$.
\end{abstract}

Keywords: Autism Spectrum Disorder, Expert System, Optimization, Fuzzy Logic Method

\section{Introduction}

The healthy development of children and in accordance with the pattern of growth and development as children get older is of course the hope of every parent for their beloved baby. However, there are several cases that occur related to the development of early childhood disorders. Some examples of child development disorders that often occur are gross motor development disorders, fine motor development disorders and autism that attacks children or what in medical terms is called autism spectrum disorder [1], [2]. The initial diagnosis that may be noticed in autistic people is how to communicate with the other person, how the child interacts with friends and the environment and the last is how the child imagines which can be seen from the results of the picture [3], [4]. These disorders can be observed and can be identified as early as possible the symptoms that occur for later consultation with experts in the field, in this case is a pediatrician or psychologist [5].

The existence of experts can be replaced with a system that stores knowledge about a field in detail and specifically which is then called an expert system [6], [7]. By inputting all the symptoms that occur in children into the knowledge base of the system, the expert system can be used to diagnose developmental disorders that occur without time and place restrictions [8], [9]. This means that consultation to find out the disorders experienced and the illness can be done anytime and anywhere [10], [11]. The symptoms that occur are used to identify the disease so that the cause of the disorder can be searched. In addition to finding the cause, it can also be used to find the most appropriate therapy for the disease and disorders experienced by the patient [12].

The initial process of the expert system is diagnosing the disease by identifying the symptoms that appear. Usually, problems arise in the diagnosis process due to unclear information which results in inaccurate disease diagnosis results. Fuzzy logic is very flexible to changes and uncertainties of the problem, so the disease diagnosis process is more suitable to use this method because of this. One of the studies that can provide solutions to these problems is research [13] which developed a fuzzy-based expert system called the Pain

Accepted by editor: 04-11-2021 | Final Revision: 22-01-2022 | Online Publication: 01-02-2022 
Intensity Prediction Expert System (PIPES). The expert this is characterized by the patient not responding to system is used to predict pain severity risk (PSR) in events experienced by others. The last symptom in this shoveling-related tasks. The results obtained are Pain variable is the lack of social and emotional connection Intensity Prediction Expert System (PIPES) can be to the surroundings [24].

implemented for the construction industry, sand mining sites, and other worksites where the work materials can be moved using a shovel manually. The use of fuzzy logic itself has been widely implemented to diagnose a disease, such as an eye disease [14], diphtheria disease [15], polyneuropathy [16], ENT disease [17], and oral and dental disease [18].

The difference between this study and previous studies is the optimization of membership degrees for the variables used to diagnose ASD, namely social interaction variables, social communication variables and imagination variables and behavioral patterns. The Mamdani method approach still applies the same theory as the Tsukamoto fuzzy method, namely by changing an uncertain value into a definite value from patient input [19]. Determination of functions, degrees of membership and representation curves can be determined independently by adjusting the conditions of the problems encountered [20]. After the value of the user input is translated using the fuzzy logic method into a definite value, the next step is to determine the probability value of each symptom/input by the user, namely patients with autism. The data used in this study were data samples from the Banyumas hospital in the period January to August 2021. There were 96 patients indicated to suffer from ASD. This is known from the initial history which concludes that some of the symptoms experienced by the patient lead to ASD. Furthermore, in this study, the data is used to optimize the degree of membership in each of the variables involved. The purpose of this study was to determine the level of accuracy of the comparison of expert diagnoses in this case psychologist and the results of this study were fuzzy logic optimization to detect ASD in 96 patients.

\section{Method}

\subsection{ASD (Autism Spectrum Disorder)}

The variables used to classify the symptoms of autism spectrum disorder are divided into 3 (three) variables [21], including: Social Interaction. Symptoms included in social interaction variables, namely inadequate social interaction which is characterized by uninspired eye contact, facial expressions that are too flat, uncontrolled movements and lack of focus, not responding when called upon, refusing to be hugged, not interested in new things such as toys, suddenly crying or laughing for no reason, playing with unusual objects such as not toys in general [22]. The second symptom is usually the patient cannot play and interact normally with peers [23]. The third symptom is that patients with ASD lack empathy,
Social Communication. For symptoms on social communication variables, the first is the delay in speaking and there is no attempt to catch up with the delay, withdrawing the hand when you want something [25]. The second symptom is able to speak but not to communicate with other people [26]. The third symptom is the frequent use of strange and repeated language. The last symptom is showing how to play is monotonous, less varied, less imaginative and less able to imitate [27]. Imagination and Behavioral Patterns. The last variable is imagination and behavior patterns, where the symptoms include the first to maintain one or more interests in a typical and excessive way [28]. The second symptom is fixation on one activity that is usually done and less useful [29]. The next symptom is that there are repetitive and unusual movements. The latter symptom is often too much focus on one part of the object [30].

\subsection{Expert System}

Fuzzy logic can be interpreted as a precise mapping of an input space into an output space [33]. Fuzzy logic is usually used for solving a complex problem by adding new input functions to the fuzzy system where the system works based on the principles and rules associated with it [34]. To deal with complex problems and difficult to define with a mathematical model with an approach reasoning process, this fuzzy system is good enough to be implemented [35]. The reasoning ability of the fuzzy system is almost similar to the ability of human reasoning where the fuzzy system can provide a response to qualitative, inaccurate and ambiguous information [36]. Some of the reasons for using fuzzy logic are that fuzzy logic is very flexible, has tolerance, is easy to understand, whereas the mathematical concepts underlying fuzzy reasoning are very simple [37]. Fuzzy reasoning can model very complex nonlinear functions and can build and apply the experience of experts directly without going through the training process [38].

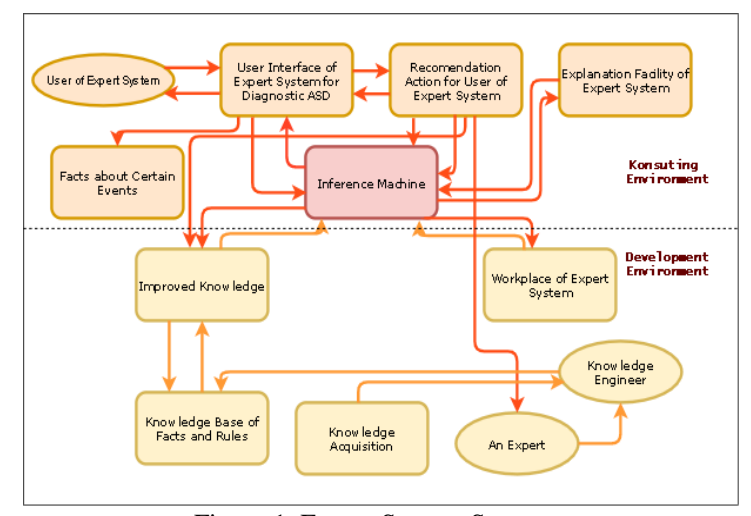

Figure 1. Expert System Structure 
Figure 1 describes the environment for consulting and used will be the value of each variable in the fuzzy set the environment for expert system development. In the [35].

consulting environment, there are several components such as an application/system user interface that can be used by expert system users to consult about something, in this case, consultation to find out autism spectrum disorder [31]. Then there is a component about the symptoms experienced by ASD sufferers in which the component is described in detail about each symptom that the patient may or may not experience [32]. There is an inference engine that exists in the expert system development environment [13]. The function of the inference engine in the expert system is used to trace the reasoning process to a condition experienced based on a knowledge base of available facts and rules [6]. In the development environment, there is expert knowledge about a field that is absorbed by knowledge engineering to be translated into facts and rules which will later be used in the knowledge base and correlated with the inference engine in the expert system [33]. In this study, the expert is a paediatrician and a psychologist who provides knowledge about autism spectrum disorder which consists of symptoms experienced and therapy that can be done by observing patients [3]. Then the knowledge of the two experts is processed into facts and rules that are placed into the knowledge base of an expert system for diagnosis of ASD by a knowledge engineer [34].

\subsection{Fuzzy Logic Method}

Fuzzy logic can be interpreted as a precise mapping of an input space into an output space [30]. Fuzzy logic is usually used for solving a complex problem by adding new input functions to the fuzzy system where the system works based on the principles and rules associated with it [31]. To deal with complex problems and difficult to define with a mathematical model with an approach reasoning process, this fuzzy system is good enough to be implemented [32]. The reasoning ability of the fuzzy system is almost similar to the ability of human reasoning where the fuzzy system can respond to qualitative, inaccurate and ambiguous information [33]. Some of the reasons for using fuzzy logic are that fuzzy logic is very flexible, has tolerance, is easy to understand, whereas the mathematical concepts underlying fuzzy reasoning are very simple [34]. Fuzzy reasoning can model very complex non-linear functions and can build and apply the experience of experts directly without going through the training process [35].

Figure 2 describes the fuzzy logic flowchart, with the following stages: The first stage is to enter the fuzzy set in the expert system for the diagnosis of ASD, then proceed with the selection of the type of membership function curve for the fuzzy set that is determined for each variable involved. Later the degree of membership

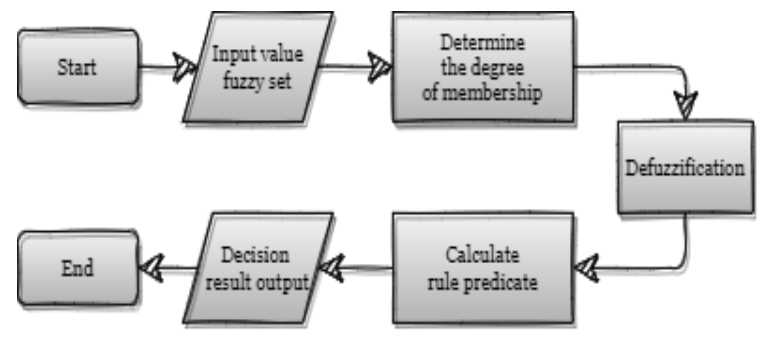

Figure 2. Fuzzy Method Flowchart

The second stage in this method is determining the degree of membership $(\mu)$ for each variable involved and making rules which will be used to calculate the predicate value of the rule $(\alpha)$. The combination of each variable with other variables that are used together with the rules made with their respective language attributes [36]. Determination of the rule using the following rules:

$$
\text { IF P And Q THEN R }
$$

To determine the next rule using these rules and adapted to the conditions of the problem.

The next step is to defuzzification by finding the value of the moment (Mn) and area (A) using the centroid method [37].

The fourth stage is calculating the predicate rule $(\alpha)$ which is used in the knowledge base of the expert system for the variables that have been inputted into the fuzzy set. The calculation of the value of the rule predicate is obtained from the process of implication of each rule. The min operation is used in the Mamdani method of implication process, while the rule predicate value is obtained by entering the minimum value of the degree of membership between the variables that have been combined in a predetermined rule [38].

$$
\begin{aligned}
& \alpha-\text { predicate }=M I N \mu(g 1), \mu(g 2), \ldots(\mu g n) \\
& \alpha-\text { predicate }=\frac{\text { upper limit }-z 1}{\text { upper limit-lower limit }}
\end{aligned}
$$

The last step in this method is to determine the output value $(Z)$ based on the membership function and analyze the composition between the rules created and create a membership function [19]. The formula used to determine the output value is as follows:

$$
Z=\frac{\sum \boldsymbol{\alpha}_{n} z_{n}}{\sum \boldsymbol{\alpha}_{n}}
$$




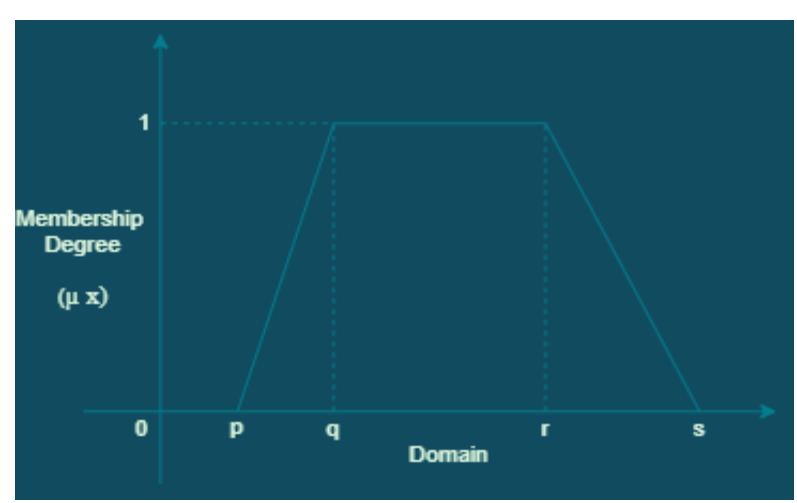

Figure 3. Trapezoidal Curve Representation

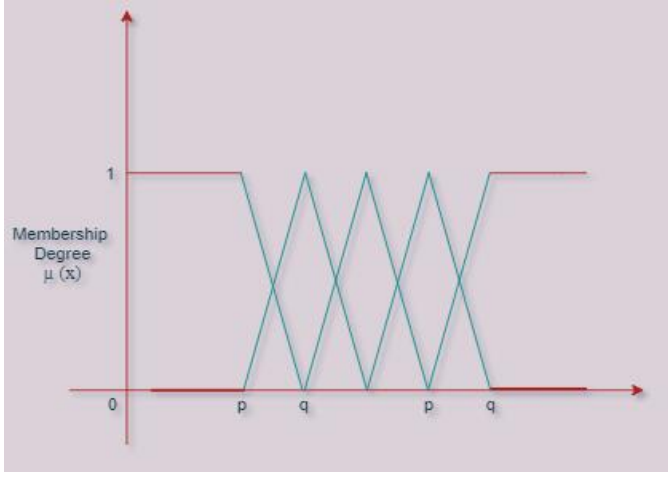

Figure 5. Shoulder Curve Representation

The trapezoidal curve representation picture above can 3. Result and Discussion be explained that the initial input is $\mathrm{x}$ as the membership value and is processed to produce a decision if [39]:

$x \leq p$ dan $x \geq q$, then the degree of membership $\mu$ (x) $=0$;

$p \leq x \leq q$, then the degree of membership is calculated using the formula:

$$
\mu(\mathrm{x})=\frac{q-x}{q-p}
$$

$q \leq x \leq r$, then the degree of membership $\mu$ (x)=1; $r \leq x \leq s$, then the degree of membership is calculated by the formula :

$$
\mu(\mathrm{x})=\frac{s-x}{s-r}
$$

Furthermore, Figure 4 describes the flowchart of the process description on the trapezoidal curve representation. While Figure 5 describes a curve in the form of a shoulder where the middle area of a variable is represented in the form of a triangle which on the right and left sides goes up and down. This shoulder curve is used to terminate an area of fuzzy variables. The left shoulder curve moves from a true statement to a false statement while the right shoulder curve moves from a false statement to a true statement [19].

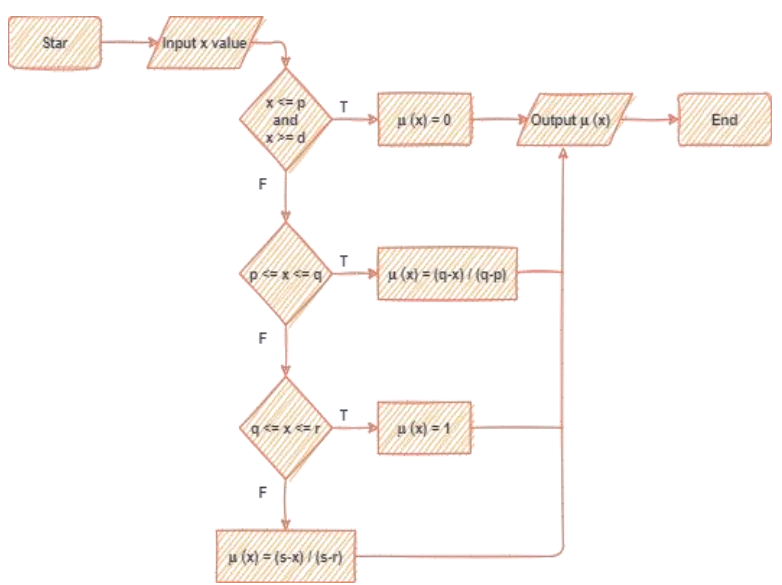

Figure 4. Trapezoidal Curve Representation Flowchart

\subsection{Fuzzy Variable}

Table 1 shows the ASD symptom code per variable, where SI code means Social Interaction variable, SC code means Social Communication and IBP code means

\begin{tabular}{|c|c|c|c|}
\hline Code & Symptom & Domain & $\begin{array}{l}\text { Value } \\
\text { Score }\end{array}$ \\
\hline \multirow[t]{2}{*}{ SI01 } & Unexcited eye contact & $3-12$ & 11 \\
\hline & & $0-8$ & 2 \\
\hline \multirow[t]{2}{*}{ SI02 } & Facial expression is too & $3-12$ & 11 \\
\hline & flat & $0-8$ & 2 \\
\hline \multirow[t]{2}{*}{ SI03 } & Uncontrolled movements & $3-12$ & 11 \\
\hline & & $0-8$ & 2 \\
\hline \multirow[t]{2}{*}{ SI04 } & Unfocused movement & $3-12$ & 11 \\
\hline & & $0-8$ & 2 \\
\hline \multirow[t]{2}{*}{ SI05 } & Does not respond when & $3-12$ & 11 \\
\hline & called & $0-8$ & 2 \\
\hline \multirow[t]{2}{*}{ SI06 } & Refusing to be hugged & $3-12$ & 11 \\
\hline & & $0-8$ & 2 \\
\hline \multirow[t]{2}{*}{ SI07 } & Not interested in new & $3-12$ & 11 \\
\hline & things & $0-8$ & 2 \\
\hline \multirow[t]{2}{*}{ SI08 } & Suddenly crying or & $3-12$ & 11 \\
\hline & laughing for no reason & $0-8$ & 2 \\
\hline \multirow[t]{2}{*}{ SI09 } & Playing with unusual & $3-12$ & 11 \\
\hline & objects & $0-8$ & 2 \\
\hline \multirow[t]{2}{*}{ SI10 } & Unable to play and & $3-12$ & 11 \\
\hline & $\begin{array}{l}\text { interact normally with } \\
\text { peers }\end{array}$ & $0-8$ & 2 \\
\hline \multirow[t]{2}{*}{ SI11 } & Lack of empathy & $3-12$ & 11 \\
\hline & & $0-8$ & 2 \\
\hline \multirow[t]{2}{*}{ SI12 } & Lack of social and & $3-12$ & 11 \\
\hline & $\begin{array}{l}\text { emotional connection to } \\
\text { the surrounding }\end{array}$ & $0-8$ & 2 \\
\hline \multirow[t]{2}{*}{ SC01 } & Speech delay & $2-6$ & 5.5 \\
\hline & & $0-4.5$ & 1.5 \\
\hline \multirow[t]{2}{*}{$\mathrm{SC} 02$} & Pull your hand when you & $2-6$ & 5.5 \\
\hline & want something & $0-4.5$ & 1.5 \\
\hline \multirow[t]{2}{*}{$\mathrm{SC} 03$} & Can talk but not for & $2-6$ & 5.5 \\
\hline & $\begin{array}{l}\text { communication with other } \\
\text { people }\end{array}$ & $0-4.5$ & 1.5 \\
\hline \multirow[t]{2}{*}{$\mathrm{SC} 04$} & Often uses strange and & $2-6$ & 5.5 \\
\hline & repetitive language & $0-4.5$ & 1.5 \\
\hline
\end{tabular}
Imagination and Behavioral Patterns. 


\begin{tabular}{llcc}
\hline Code & \multicolumn{1}{c}{ Symptom } & Domain & $\begin{array}{c}\text { Value } \\
\text { Score }\end{array}$ \\
\hline SC05 & How to play is & $2-6$ & 5.5 \\
& $\begin{array}{l}\text { monotonous, less varied, } \\
\text { less imaginative }\end{array}$ & $0-4.5$ & 1.5 \\
SC06 & Less able to imitate games & $2-6$ & 5.5 \\
& taught/shown by others & $0-4.5$ & 1.5 \\
IBP01 & $\begin{array}{l}\text { Maintaining one or more } \\
\text { interests in a characteristic }\end{array}$ & $1-4$ & 3.75 \\
& and exaggerated manner & & 1 \\
IBP02 & $\begin{array}{l}\text { Stuck in one activity that } \\
\text { is usually done and less }\end{array}$ & $1-4$ & 3.75 \\
& useful & & 1 \\
IBP03 & There are repetitive and & $1-4$ & 3.75 \\
& unusual movements & $0-2.75$ & 1 \\
IBP04 & Often too focused on one & $1-4$ & 3.75 \\
& part of the object & $0-2.75$ & 1 \\
\hline
\end{tabular}

\subsection{Criteria Curve}

Social interaction variables, social communication variables and imagination variables and behavior patterns were divided into two categories with different upper and lower threshold values. If there are symptoms experienced, it means that it is true (1) and there are no symptoms experienced, it means that it is false $(0)$. The membership function will be formed based on the domain of each criterion variable in the range of values for each symptom. Domains that have been formed and shown in table 2 are used to determine the membership function formula. For the membership function and the fuzzy set membership function formula, each variable is depicted on the fuzzy set curve, Fig. 6.

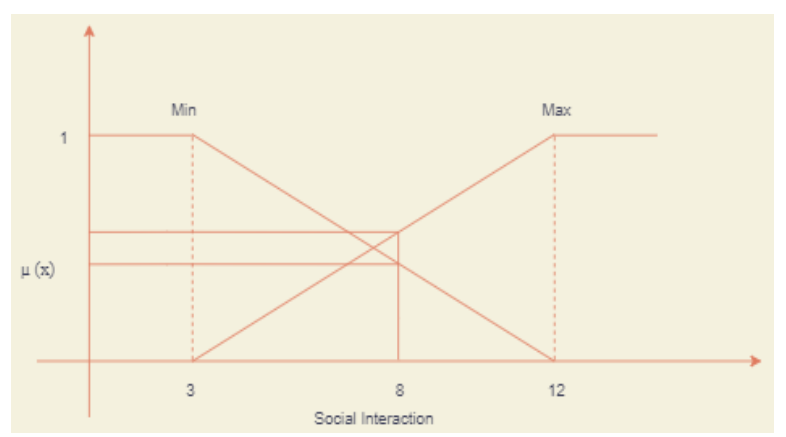

Figure 6. Fuzzy Set Curve of Social Interaction Variables

Membership Function Social Interaction Variable Minimum

$$
\mu(\mathrm{x})=\left\{\begin{array}{cc}
1, & x \leq 3 \\
\frac{12-x}{9}, & \leq x \leq 12 \\
0, & x \geq 12
\end{array}\right.
$$

Membership Function Social Interaction Variable Maximum

$$
\mu(\mathrm{x})=\left\{\begin{array}{cc}
0, & x \leq 3 \\
\frac{x-3}{9}, & \leq x \leq 12 \\
1, & x \geq 12
\end{array}\right.
$$

For social interaction variables, the fuzzy set curve shows 2 (two) categories, namely there is one symptom shown by the patient and none of the symptoms shown by the patient. The lower threshold value is at the point and the upper threshold value is at the point.

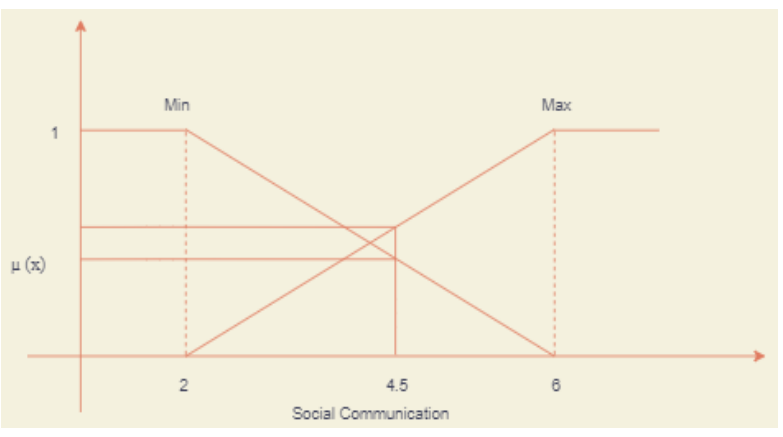

Figure 7. The Curve of Fuzzy Set of Social Communication Variables

Membership Function Social Communication Variable Minimum

$$
\mu(\mathrm{x})= \begin{cases}1, & x \leq 2 \\ \frac{6-x}{4}, & \leq x \leq 6 \\ 0, & x \geq 6\end{cases}
$$

Membership Function Social Communication Variable Maximum

$$
\mu(x)=\left\{\begin{array}{cc}
0, & x \leq 2 \\
\frac{x-2}{4}, & \leq x \leq 6 \\
1, & x \geq 6
\end{array}\right.
$$

Similar to the social communication variable, for the social communication variable, the fuzzy set curve shows 2 (two) categories, namely there is one symptom shown by the patient and none of the symptoms shown by the patient. The lower threshold value is at the point and the upper threshold value is at the point.

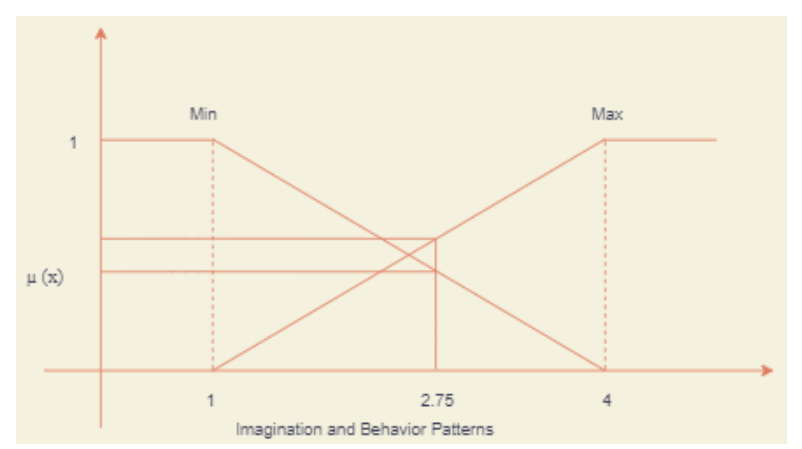

Figure 8. Fuzzy Set Curves of Imagination Variables and Behavioral Patterns

Membership Function Imagination Variables and Behavioral Patterns Minimum

$$
\mu(\mathrm{x})=\left\{\begin{array}{cc}
1, & x \leq 1 \\
\frac{4-x}{3}, & 1 \leq x \leq 4 \\
0, & x \geq 4
\end{array}\right.
$$


Membership Function Imagination Variables and For SI variables:

Behavioral Patterns Maximum

$$
\mu(\mathrm{x})=\left\{\begin{array}{cc}
0, & x \leq 1 \\
\frac{x-1}{3}, & 1 \leq x \leq 4 \\
1, & x \geq 4
\end{array}\right.
$$

For ASD disease indication variables, the fuzzy set curve shows 2 (two) categories, namely ASD indicated and not ASD indicated. The figure for the membership function curve is as follows:

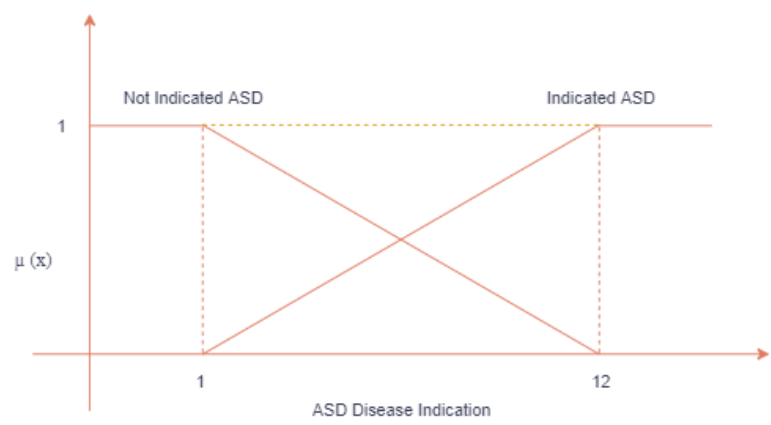

Figure 9. The Curve of Fuzzy Set of ASD Disease Indication Variables

Membership Function Not Indicated ASD Disease

$$
\mu(\mathrm{z})=\left\{\begin{array}{cc}
1, & z \leq 2 \\
\frac{13-z}{11}, & 2 \leq z \leq 13 \\
0, & z \geq 4
\end{array}\right.
$$

Membership Function Indicated ASD Disease

$$
\mu(\mathrm{z})= \begin{cases}0, & z \leq 2 \\ \frac{z-2}{11}, & 2 \leq z \leq 13 \\ 1, & z \geq 13\end{cases}
$$

\subsection{Predicate Rule, Defuzzification and Output Value}

The data of 22 disease symptoms as shown in table 1 is used to enter in diagnosing ASD which has the same parameters, namely for codes SI01 to SI12 it has 2 parameters, namely Yes and No, SC01 to SC06 has 2 parameters, namely Yes and No and IBP01 to IBP04 has 2 parameters, namely Yes and No.

For example, the case is a patient with an SI variable of 9, a SC variable of 5.5 and an IBP variable of 3 , so to solve the case, start by determining the rules used to diagnose ASD. The application of the implication function used is the MIN rule, while the method used to perform the composition between all the rules is the MAX method. Then proceed with calculating the predicate value obtained from the minimum value of the fuzzification results for each rule that matches the input value of the symptoms experienced using equation (1), and continues to find the $Z$ value with equation (2), so that in this study the following examples of calculation:

$$
\begin{aligned}
& \mu \min (9)=\frac{12-9}{9}=0.333 \\
& \mu \max (9)=\frac{9-3}{9}=0.667
\end{aligned}
$$

For SC variables:

$$
\begin{aligned}
& \mu \min (5.5)=\frac{6-5.5}{4}=0.125 \\
& \mu \max (5.5)=\frac{5.5-2}{4}=0.875
\end{aligned}
$$

For IBP variables:

$$
\begin{aligned}
& \mu \min (3)=\frac{4-3}{3}=0.333 \\
& \mu \max (3)=\frac{3-1}{3}=0.667
\end{aligned}
$$

Table 3 shows the rules of the expert system for diagnosing autism spectrum disorders that attack children. The rule is built after the fuzzy set for each variable is determined by its value. This expert system rule is one part of the expert system structure, namely the knowledge base. The knowledge base is very necessary for the design of expert systems because through this knowledge base it is defined input from the user in the form of symptoms, translated through rules and determined values to then produce conclusions on a problem encountered. For this expert system, the output is a recommendation for therapy used for patients with ASD (Autism Spectrum Disorder).

Table 3 below is a rule table for the diagnosis of ASD with fuzzification values.

Table 2. Result of Rules According to Symptom Input

\begin{tabular}{cccc}
\hline Code & Rule & Fuzzifikasi & Consequent \\
\hline R01 & If SI max and SC & $0.667 ;$ & Indicated \\
& max and IBP max & $0.875 ;$ & ASD \\
& then & 0.667 & \\
R02 & If SI max and SC & $0.667 ;$ & Indicated \\
& max and IBP min & $0.875 ;$ & ASD \\
& then & 0.333 & \\
R03 & If SI max and SC & $0.667 ;$ & Indicated \\
& min and IBP max & $0.125 ;$ & ASD \\
& then & 0.667 & \\
R04 & If SI min and SC & $0.333 ;$ & Indicated \\
& max and IBP max & $0.875 ;$ & ASD \\
& then & 0.667 & \\
R05 & If SI max and SC & $0.667 ;$ & Not \\
& min and IBP min & $0.125 ;$ & Indicated \\
& then & 0.333 & ASD \\
R06 & If SI min and SC & $0.333 ;$ & Not \\
& max and IBP min & $0.875 ;$ & Indicated \\
& then & 0.333 & ASD \\
R07 & If SI min and SC & $0.333 ;$ & Not \\
& min and IBP max & $0.125 ;$ & Indicated \\
& then & 0.667 & ASD \\
R08 & If SI min and SC & $0.333 ;$ & Not \\
& min and IBP min & $0.125 ;$ & Indicated \\
& then & 0.333 & ASD \\
\hline \multirow{4}{*}{ ind }
\end{tabular}

The next step is to find the $\mathrm{z}$ value for each rule by using the MIN function in the implication function application Then perform the calculation of $\alpha$-predicate, obtained 
from the minimum value of the fuzzification results for [R07] If SI min and SC min and IBP max then Not each rules that match the symptom input. Process Indicated ASD

fuzzification calculation to find $\alpha$-predicate using equation (1), and after getting the value of $\alpha$-predicate can be the value of $\mathrm{z}$ is obtained by equation (2), it is shown as following:

$\alpha_{07}=\operatorname{MIN}(\mu \min (S I)) \cap(\mu \min (S C)) \cap(\mu \max (I B P))$

$\alpha_{07}=\operatorname{MIN}(0.333) \cap(0.125) \cap(0.667)=0.125$

[R01] If SI max and SC max and IBP max then Indicated $\frac{13-z 7}{11}=0.125$ ASD $z 7=13-(0.125 * 11)=11.625$

$\alpha_{01}=\operatorname{MIN}(\mu \max (S I)) \cap(\mu \max (S C)) \cap(\mu \max (I B P))$

$\alpha_{01}=\operatorname{MIN}(0.667) \cap(0.875) \cap(0.667)=0.667$

[R08] If SI min and SC min and IBP min then Not Indicated ASD

For Indicated ASD:

$\alpha_{08}=\operatorname{MIN}(\mu \min (S I)) \cap(\mu \min (S C)) \cap(\mu \min (I B P))$

$\frac{z 1-2}{11}=0.667$

$z 1=(0.667 * 11)+2=9.337$

$\alpha_{08}=\operatorname{MIN}(0.333) \cap(0.125) \cap(0.333)=0.125$

[R02] If SI max and SC max and IBP min then Indicated

\section{ASD}

$\alpha_{02}=\operatorname{MIN}(\mu \max (S I)) \cap(\mu \max (S C)) \cap(\mu \min (I B P))$

$\alpha_{02}=\operatorname{MIN}(0.667) \cap(0.875) \cap(0.333)=0.333$

For Indicated ASD:

$\frac{z 2-2}{11}=0.333$

$z 2=(0.333 * 11)+2=5.663$

[R03] If SI max and SC min and IBP max then Indicated ASD

$\alpha_{03}=\operatorname{MIN}(\mu \max (S I)) \cap(\mu \min (S C)) \cap(\mu \max (I B P))$

$\alpha_{03}=\operatorname{MIN}(0.667) \cap(0.125) \cap(0.667)=0.667$

For Indicated ASD:

$\frac{z 3-2}{11}=0.125$

$\begin{gathered}11 \\ z 3\end{gathered}=(0.125 * 11)+2=3.375$

[R04] If SI min and SC max and IBP max then Indicated ASD

$\alpha_{04}=\operatorname{MIN}(\mu \min (S I)) \cap(\mu \max (S C)) \cap(\mu \max (I B P))$

$\alpha_{04}=\operatorname{MIN}(0.333) \cap(0.875) \cap(0.667)=0.333$

For Indicated ASD:

$\frac{z 4-2}{11}=0.333$

$z^{11}=(0.333 * 11)+2=5.663$

[R05] If SI max and SC min and IBP min then Not Indicated ASD

$\alpha_{05}=\operatorname{MIN}(\mu \max (S I)) \cap(\mu \min (S C)) \cap(\mu \min (I B P))$

$\alpha_{05}=\operatorname{MIN}(0.667) \cap(0.125) \cap(0.333)=0.125$

For Not Indicated ASD:

$\frac{13-z 5}{11}=0.125$

$z 5^{11}=13-(0.125 * 11)=11.625$

[R06] If SI min and SC max and IBP min then Not Indicated ASD

$\alpha_{06}=\operatorname{MIN}(\mu \min (S I)) \cap(\mu \max (S C)) \cap(\mu \min (I B P))$

$\alpha_{06}=\operatorname{MIN}(0.333) \cap(0.875) \cap(0.333)=0.333$

For Not Indicated ASD:

$\frac{13-z 6}{11}=0.333$

$z 6^{11}=13-(0.333 * 11)=9.337$
For Not Indicated ASD:

$\frac{13-z 8}{11}=0.125$

$z 8=13-(0.125 * 11)=11.625$

The following are the results of the calculation of $\alpha$ predicate and $\mathrm{z}$ value for R01 until R08 which are shown in table 4.

\begin{tabular}{|c|c|c|c|}
\hline Code & Rule & $\begin{array}{c}\alpha \text {-predicate } \\
\text { Value }\end{array}$ & $\begin{array}{c}z \\
\text { Value }\end{array}$ \\
\hline R01 & $\begin{array}{l}\text { If SI max and SC max } \\
\text { and IBP max then }\end{array}$ & 0.667 & 9.337 \\
\hline R02 & $\begin{array}{l}\text { If SI max and SC max } \\
\text { and IBP min then }\end{array}$ & 0.333 & 5.663 \\
\hline R03 & $\begin{array}{l}\text { If SI max and SC min } \\
\text { and IBP max then }\end{array}$ & 0.125 & 3.375 \\
\hline R04 & $\begin{array}{l}\text { If SI min and SC max } \\
\text { and IBP max then }\end{array}$ & 0.333 & 5.663 \\
\hline R05 & $\begin{array}{l}\text { If SI max and SC min } \\
\text { and IBP min then }\end{array}$ & 0.125 & 11.625 \\
\hline R06 & $\begin{array}{l}\text { If SI min and SC max } \\
\text { and IBP min then }\end{array}$ & 0.333 & 9.337 \\
\hline R07 & $\begin{array}{l}\text { If SI min and SC min } \\
\text { and IBP max then }\end{array}$ & 0.125 & 11.625 \\
\hline R08 & $\begin{array}{l}\text { If } \mathrm{SI} \text { min and SC min } \\
\text { and IBP min then }\end{array}$ & 0.125 & 11.625 \\
\hline
\end{tabular}

Then the last step of calculating the fuzzy logic method is to find the $\mathrm{Z}$ value using equation (3) based on the membership function and compositional analysis between existing rules, then the $\mathrm{Z}$ value is obtained by:

$Z=\frac{0.667 * 9.337+0.333 * 5.663+\cdots+0.125 * 11.625}{0.667+0.333+\cdots+0.125}=8.26$

From the calculation above, it can be concluded that the diagnosis of the fuzzy logic disease has a value for positive patients of 8.26. Based on the results of a trial of 96 patients, 77 patients were diagnosed with ASD and 19 patients were not diagnosed with ASD. These results were compared with expert diagnoses with 96 data from the same patient, where an expert in this case a psychologist based on the same variable indicated that there were 85 patients with ASD and 11 patients who were not indicated to stay with ASD. It can be concluded that the ASD diagnosis has been successfully carried out 
using the fuzzy logic method with a precision of $94.4 \%$, [7] a recall precision of $65.4 \%$ and an error rate of $3.05 \%$.

Table 4. Confussion Matrix

\begin{tabular}{cccc}
\hline & & \multicolumn{2}{c}{ Fuzzy Prediction } \\
& & $\mathrm{P}$ & $\mathrm{N}$ \\
Expert & $\mathrm{T}$ & 85 & 11 \\
Data & $\mathrm{F}$ & 5 & 45 \\
\hline
\end{tabular}

To calculate the accuracy level of diagnosis results by experts with fuzzy prediction results using the equation below:

$$
\begin{gathered}
\text { Accuracy }=\frac{\text { total disease according to expert diagnosis }}{\text { total fuzzy prediction result }} * 100 \% \\
\text { Accuracy }=\frac{77}{85} * 100 \%=90.59 \%
\end{gathered}
$$

Based on these predictions, ASD positive patients receive therapy according to the direction of experts and for future monitoring, it must still be carried out according to expert recommendations.

\section{Conclusion}

The fuzzy calculation error rate is relatively small, so this expert system can be used in helping the public to find out the symptoms of autism early on because the precision is $94.4 \%$, the recall precision is $65.4 \%$ and the error rate is $3.05 \%$, while the diagnostic accuracy between experts with the fuzzy method is $90.59 \%$. Further consultation with experts or child psychiatrists must still be carried out for the monitoring process in the future

\section{References}

[1] B. Razi, D. Imani, M. Hassanzadeh Makoui, R. Rezaei, and S. Aslani, "Association between MTHFR gene polymorphism and susceptibility to autism spectrum disorders: Systematic review and meta-analysis," Res. Autism Spectr. Disord., vol. 70, no. October 2019, p. 101473, 2020, doi: 10.1016/j.rasd.2019.101473.

[2] B. M. DeJesus, R. C. Oliveira, F. O. de Carvalho, J. de Jesus Mari, R. M. Arida, and L. Teixeira-Machado, "Dance promotes positive benefits for negative symptoms in autism spectrum disorder (ASD): A systematic review," Complement. Ther. Med., vol. 49, no. September 2019, 2020, doi: 10.1016/j.ctim.2020.102299.

[3] E. A. Wise, "Aging in Autism Spectrum Disorder," Am. J. Geriatr. Psychiatry, 2019, doi: 10.1016/j.jagp.2019.12.001.

[4] L. Xu, Q. Hua, J. Yu, and J. Li, "Classification of autism spectrum disorder based on sample entropy of spontaneous functional near infra-red spectroscopy signal," Clin. Neurophysiol., 2020, doi: 10.1016/j.clinph.2019.12.400.

[5] D. Aprilia, A. Johar, and Pudji Hartuti, "Sitem Pakar Diagnosa Autisme pada Anak," Rekursif, vol. 2, no. Sistem Pakar, pp. 92 98, 2014.

[6] B. F. Yanto, I. Werdiningsih, and E. Purwanti, "Aplikasi Sistem Pakar Diagnosa Penyakit Pada Anak Bawah Lima Tahun Menggunakan Metode Forward Chaining," J. Inf. Syst. Eng. Bus. Intell., vol. 3, no. 1, p. 61, 2017, doi: 10.20473/jisebi.3.1.61-67.
R. Rusdiansyah, S. Setiawan, and M. Badrul, "Diabetes Mellitus Diagnosis Expert System With Web-Based Forward Chaining," SinkrOn, vol. 3, no. 2, p. 61, Mar. 2019, doi: 10.33395/sinkron.v3i2.10055.

[8] S. Dai et al., "SeDeM expert system for directly compressed tablet formulation: A review and new perspectives," Powder Technol., vol. 342, pp. 517-527, 2019, doi: 10.1016/j.powtec.2018.10.027.

[9] M. Castelli, L. Manzoni, L. Vanneschi, and A. Popovič, "An expert system for extracting knowledge from customers' reviews: The case of Amazon.com, Inc.," Expert Syst. Appl., vol. 84, pp. 117-126, 2017, doi: 10.1016/j.eswa.2017.05.008.

[10] Y. Liu, C. M. Eckert, and C. Earl, A review of fuzzy AHP methods for decision-making with subjective judgements, vol. 161. Elsevier Ltd, 2020.

[11] F. Dweiri, S. Kumar, S. Ahmed, and V. Jain, "Corrigendum to " Designing an integrate d AHP base d decision support system for supplier selection in automotive industry 'Expert Systems," Expert Syst. Appl., vol. 72, pp. 467-468, 2017, doi: 10.1016/j.eswa.2016.12.025.

[12] L. P. Wanti, I. N. Azroha, and M. N. Faiz, "Implementasi User Centered Design Pada Sistem Pakar Diagnosis Gangguan Perkembangan Motorik Kasar Pada Anak Usia Dini," Media Apl., vol. 11, no. 1, pp. 1-10, 2019.

[13] A. H. Oluwole, A. A. Adekunle, A. O. Olasunkanmi, and A. O. Adeodu, "A shoveling-related pain intensity prediction expert system for workers' manual movement of material," Int. J. Technol., vol. 7, no. 4, pp. 603-615, 2016, doi: 10.14716/ijtech.v7i4.2208

[14] P. Ananta Dama Putra, I. K. Adi Purnawan, and D. Purnami Singgih Putri, "Sistem Pakar Diagnosa Penyakit Mata dengan Fuzzy Logic dan Naïve Bayes," J. Ilm. Merpati (Menara Penelit. Akad. Teknol. Informasi), vol. 6, no. 1, p. 35, 2018, doi: 10.24843/jim.2018.v06.i01.p04.

15] S. Isna Fitria Ali, R. Rizal Isnanto, and A. Budi Prasetijo, "Sistem Pakar Diagnosis Penyakit Difteri Menggunakan Logika Fuzzy," pp. 89-104, 2020, [Online]. Available: https://dspace.uii.ac.id/handle/123456789/28778.

[16] E. Suanto, M. Sidqon, and F. Astuti Hermawati, "Sistem Diagnosa Berbasis Fuzzy Pada Penyakit Polineoropati Akibat Diabetes Melitus," vol. 13, 2017.

[17] F. Ekajaya, N. Hidayat, and M. Tri Ananta, "Diagnosis Penyakit THT Menggunakan Metode Fuzzy Tsukamoto Berbasis Android," J. Pengemb. Teknol. Inf. dan Ilmu Komput. Univ. Brawijaya, vol. 2, no. 10, pp. 2361-2365, 2018.

[18] A. Makarios and M. I. Prasetiyowati, "Rancang Bangun Sistem Pakar untuk Diagnosis Penyakit Mulut dan Gigi dengan Metode Fuzzy Logic," J. Ultim., vol. 4, no. 2, pp. 1-6, 2012, doi: 10.31937/ti.v4i2.313

[19] A. Setyono and S. N. Aeni, "Development of decision support system for ordering goods using fuzzy Tsukamoto," Int. J. Electr. Comput. Eng., vol. 8, no. 2, pp. 1182-1193, 2018, doi: 10.11591/ijece.v8i2.pp1182-1193.

[20] D. Kurnianingtyas, W. F. Mahmudy, A. W. Widodo, F. Ilmu, K. Universitas, and A. Genetika, "Optimasi Derajat Keanggotaan Fuzzy Tsukamoto Menggunakan," vol. 4, no. 1, pp. 8-18, 2017.

[21] S. Ghozy et al., "Association of breastfeeding status with risk of autism spectrum disorder: A systematic review, dose-response analysis and meta-analysis," Asian J. Psychiatr., vol. 48, p. 101916, 2020, doi: 10.1016/j.ajp.2019.101916.

[22] E. Puerto, J. Aguilar, C. López, and D. Chávez, "Using Multilayer Fuzzy Cognitive Maps to diagnose Autism Spectrum Disorder,” Appl. Soft Comput. J., vol. 75, pp. 58-71, 2019, doi: 10.1016/j.asoc.2018.10.034.

[23] B. Eskandari, H. Pouretemad, M. Mousavi, and H. Farahani, "Common elements of parent management training programs for preschool children with autism spectrum disorder," Asian J. Psychiatr., vol. 52, no. November 2019, p. 102149, 2020, doi: 10.1016/j.ajp.2020.102149.

[24] A. Alivar et al., "Smart bed based daytime behavior prediction in Children with autism spectrum disorder - A Pilot Study," 
Med. Eng. Phys., vol. 83, pp. 15-25, 2020, doi: 10.1016/j.medengphy.2020.07.004.

[25] L. de Vries, I. Fouquaet, B. Boets, G. Naulaers, and J. Steyaert, "Autism spectrum disorder and pupillometry: A systematic review and meta-analysis," Neurosci. Biobehav. Rev., vol. 120, pp. 479-508, 2021, doi: 10.1016/j.neubiorev.2020.09.032.

[26] J. A. Cascia and J. J. Barr, "Associations among parent and teacher ratings of systemizing, vocabulary and executive function in children with autism spectrum disorder," Res. Dev. Disabil., vol. 106, no. July, p. 103779, 2020, doi: 10.1016/j.ridd.2020.103779.

[27] A. Gandotra, E. Kotyuk, A. Szekely, K. Kasos, L. Csirmaz, and R. Cserjesi, "Fundamental movement skills in children with autism spectrum disorder: A systematic review," Res. Autism Spectr. Disord., vol. 78, no. July, p. 101632, 2020, doi: 10.1016/j.rasd.2020.101632.

[28] D. Samanta, "An Updated Review of Tuberous Sclerosis Complex-Associated Autism Spectrum Disorder," Pediatr. Neurol., vol. 109, no. xxxx, pp. 4-11, 2020, doi: 10.1016/j.pediatrneurol.2020.03.008.

[29] M. M. Vandewouw, E. J. Choi, C. Hammill, J. P. Lerch, E. Anagnostou, and M. J. Taylor, "Changing Faces: Dynamic Emotional Face Processing in Autism Spectrum Disorder Across Childhood and Adulthood," Biol. Psychiatry Cogn. Neurosci. Neuroimaging, 2020, doi: 10.1016/j.bpsc.2020.09.006.

[30] J. A. Andoy Galvan et al., "Mode of delivery, order of birth, parental age gap and autism spectrum disorder among Malaysian children: A case-control study," Heliyon, vol. 6, no. 10, p. e05068, 2020, doi: 10.1016/j.heliyon.2020.e05068.

[31] S. H. Liao, "Expert system methodologies and applications-a decade review from 1995 to 2004," Expert Syst. Appl., vol. 28 , no. 1, pp. 93-103, 2005, doi: 10.1016/j.eswa.2004.08.003.

[32] K. B. Ooi and G. W. H. Tan, "Mobile technology acceptance model: An investigation using mobile users to explore smartphone credit card," Expert Syst. Appl., vol. 59, pp. 33-46, 2016, doi: 10.1016/j.eswa.2016.04.015.
[33] D. Santra, S. K. Basu, J. K. Mandal, and S. Goswami, "Rough set based lattice structure for knowledge representation in medical expert systems: Low back pain management case study," Expert Syst. Appl., vol. 145, p. 113084, 2020, doi: 10.1016/j.eswa.2019.113084.

[34] L. P. Wanti and S. Romadlon, "Implementasi Forward Chaining Method Pada Sistem Pakar Untuk Deteksi Dini Penyakit Ikan," Infotekmesin, vol. 11, no. 02, pp. 74-79, 2020, doi: 10.35970/infotekmesin.v11i2.248.

[35] H. M. Lyu, W. H. Zhou, S. L. Shen, and A. N. Zhou, "Inundation risk assessment of metro system using AHP and TFN-AHP in Shenzhen," Sustain. Cities Soc., vol. 56, p. 102103, 2020, doi: 10.1016/j.scs.2020.102103.

[36] H. T. Phan, N. T. Nguyen, V. C. Tran, and D. Hwang, "An approach for a decision-making support system based on measuring the user satisfaction level on Twitter," Inf. Sci. (Ny)., vol. 561, pp. 243-273, 2021, doi: 10.1016/j.ins.2021.01.008.

[37] C. Chiang and Y. Chen, "Neural network fuzzy sliding mode control of pneumatic muscle actuators," Eng. Appl. Artif. Intell., vol. 65, no. June 2017, pp. 68-86, 2017, doi: 10.1016/j.engappai.2017.06.021.

[38] M. T. Al Nahyan, Y. E. Hawas, M. S. Mohammad, and B. Basheerudeen, "A decision-support system for identifying the best contractual delivery methods of mega infrastructure developments," ICEIS 2018 - Proc. 20th Int. Conf. Enterp. Inf. Syst., vol. 1, no. Iceis 2018, pp. 407-414, 2018, doi: $10.5220 / 0006694704070414$

[39] E. Danish and M. Onder, "Application of Fuzzy Logic for Predicting of Mine Fire in Underground Coal Mine," Saf. Health Work, vol. 11 , no. 3, pp. 322-334, 2020, doi: 10.1016/j.shaw.2020.06.005. 